\title{
Os paradoxos do desejo (na formação) do psicanalista
}

\author{
Andrea Franco Milagres
}

\begin{abstract}
Resumo
Em 1964, Lacan funda sua Escola, cujo objetivo primeiro era resgatar a sega cortante da verdade freudiana, denunciando os desvios e as concessões que amorteciam seu progresso, para que assim a psicanálise pudesse responder pelo dever que lhe compete no mundo. Estabelecidas as linhas gerais do funcionamento da Escola, em 1971 acrescenta uma nota anexa, na qual discute principalmente o problema da formação do psicanalista, ponto em que os analistas da Internacional desviaram-se. Se, na Internacional, a formação do psicanalista resulta da obediência e da observância a uma série de regras padronizadas dentro de uma estrutura hierárquica, na Escola de Lacan a formação do psicanalista deve necessariamente incluir o fato de que "a psicanálise constitui-se como didática pelo querer do sujeito, e que ele deve ser advertido de que análise contestará esse querer, na medida mesma da aproximação do desejo que ele encerra" (Lacan, 1971/2003d, p. 240). Desse modo, no que diz respeito à formação do psicanalista, Lacan introduz aí a função do desejo, em contraponto à normatização ipeista. Interessa, portanto, discutir essa formulação de 1971, articulando-a ao que estava acenado por Lacan na "Proposição de 9 de outubro", de que na formação do psicanalista há um real em jogo. Se, na Internacional, esse real é sistematicamente evitado ou negado, na Escola de Lacan é a pedra a ser lapidada. Gostaria, portanto, de pensar sobre o tratamento a ser dado a esse real em jogo em uma psicanálise, que pode fazer advir o desejo do psicanalista, nunca estabelecido a priori, mas produto de uma extração.
\end{abstract}

\section{Palavras-chave:}

Formação; Desejo do psicanalista; Real; Escola de psicanálise. 


\title{
The paradoxes of the desire (in the formation) of a psychoanalyst
}

\begin{abstract}
Lacan founded his School in 1964, in order to restore the cutting edge of Freudian truth, denouncing the deviations and compromises that encumbered its progress, so that psychoanalysis could assume its duty in the world. After establishing the general rules for the functioning of his school, in 1971 Lacan added a note, in which he expressed the problem of a psychoanalyst formation, a strong issue that had been deviated by the analysts from the International Association. If the psychoanalyst's formation in the International resulted in the obedience and the observance of several standardized rules from a hierarchical structure, in Lacan's School that formation must necessarily include the fact that "psychoanalysis is constituted as didactics by the desire of each one, and that he/she must be warned that the analysis is going to challenge that desire while he/she gets closer to it" (Lacan, 1971/2003d, p. 240). So, refering to the formation of a psychoanalyst, Lacan added the function of the desire, against that IPA standardization. Therefore, it is interesting to discuss that 1971's formulation, articulating it to what Lacan was warning in his "Proposition of 9 of October", that there was a real in a psychoanalyst's formation. If in the International School this obstacle used to be avoided or denied systematically, in Lacan's School it would be a stone in lapidation. This paper deals with this real into a psychoanalysis treatment, which can bring psychoanalyst's desire, never established as a priori, but the product of an extraction.
\end{abstract}

\section{Keywords:}

Formation; Psychoanalyst's desire; Obstacle; School of psychoanalysis.

\section{Las paradojas del deseo (en la formación) del psicoanalista}

\section{Resumen}

En 1964 Lacan funda su Escuela, cuyo objetivo primero era rescatar la sega cortante de la verdad freudiana, denunciando las desviaciones y concesiones que amortiguaban su progreso, para que así el psicoanálisis pudiera responder por el deber que le corresponde en el mundo. Establecidas las líneas generales del funcionamiento de la Escuela, en 1971 se añade una nota adjunta, en la que Lacan discute principalmente el problema de la formación del psicoanalista, punto donde los analistas de la Internacional se desviaron. Si en la Internacional la formación del psicoanalista resulta de la obediencia y la observancia a una serie de reglas estandarizadas dentro de una estructura jerárquica, en la Escuela de Lacan la formación del psicoanalista debe necesariamente incluir el hecho de que "el psicoanálisis se constituye como didáctica por el querer del sujeto, y que él debe ser advertido de qué análisis contestará ese querer, en la medida 
misma de la aproximación del deseo que él encierra" (Lacan, 1971/2003d, p. 240). De este modo, en lo que se refiere a la formación del psicoanalista, Lacan introduce allí la función del deseo, en contrapunto a la normalización ipeista. Interesa, por lo tanto, discutir esta formulación de 1971, articulándola al que estaba caracterizado por Lacan en la "Proposición del 9 de octubre", de que en la formación del psicoanalista hay un real en juego. Si en la Internacional este real es sistemáticamente evitado o negado, en la Escuela de Lacan es la piedra a ser lapidada. Por lo tanto, me gustaría pensar en el trato que se debe dar a este real en juego en el psicoanálisis, que puede hacer surgir el deseo del psicoanalista, nunca establecido a priori, sino producto de una extracción.

\section{Palabras clave:}

Formación; Deseo del psicoanalista; Real; Escuela de psicoanálisis.

\section{Les paradoxes du désir (dans la formation) du psychanalyste}

\section{Résumé}

Lacan fonda son Ecole en 1964 avec l'objectif de sauver le soc tranchant de la vérité freudienne, d'en dénoncer les déviances et les concessions qui avaient entravé son avancée afin que la psychanalyse puisse assumer son rôle au sein du monde. Une fois établies les lignes générales du fonctionnement de l'Ecole, Lacan y ajouta une note en 1971 dans laquelle il aborda essentiellement le problème de la formation du psychanalyste, point duquel les analystes de l'Association Internationale s'étaient éloignés. Pour cette Association, la formation du psychanalyste résulte de l'obéissance et de l'observation à une série de règles standards dans le cadre d'une structure hiérarchique alors que dans l'Ecole de Lacan, la formation du psychanalyste doit obligatoirement inclure le fait que «la psychanalyse est constituée comme didactique par le vouloir du sujet et qu'il doit être averti que l'analyse contestera ce vouloir, à mesure même de l'approche du désir qu'il recèle » (Lacan, 1971/2003d, p. 240). A propos de la formation du psychanalyste, Lacan introduit donc ici la fonction du désir en opposition aux normes de l'IPA. Il est toutefois intéressant de discuter la formulation de 1971 en association avec ce que Lacan signalait dans la «Proposition du 9 octobre ", dans le sens que le réel est en jeu dans la formation du psychanalyste. Si ce réel est systématiquement évité ou nié par l'Association Internationale, au sein de l'Ecole de Lacan, il s'agit de la pierre à lapider. J'aimerais donc penser au traitement à donner à ce réel en jeu au sein d'une psychanalyse, qui peut faire surgir le désir du psychanalyste, jamais établi à priori mais produit d'une extraction.

\section{Mots-clés :}

Formation ; Désir du psychanalyste; Réel ; École de psychanalyse. 
Não me importa a palavra, esta corriqueira. Quero é o esplêndido caos de onde emerge a sintaxe, os sítios escuros onde nasce o "de", o "aliás", o "o", o "porém" e o "que", esta incompreensível muleta que me apoia.

Quem entender a linguagem entende Deus cujo filho é Verbo. Morre quem entender. A palavra é disfarce de uma coisa mais grave, surda-muda, foi inventada para ser calada.

Em momentos de graça, infrequentíssimos, se poderá apanhá-la, um peixe vivo com a mão.

Puro susto e terror. Adélia Prado

Vou tomar como interlocutores três textos de Lacan: "Ato de fundação" (1964/2003a) e sua nota anexa (1971/2003d), "Proposição de 9 de outubro", de 1967 (1967b/2003b), e "Discurso na Escola Freudiana de Paris", de 1970 (1970/2003c), que me são caros, visto que neles encontro preciosas indicações sobre o tema da formação do psicanalista e sobre a passagem de psicanalisante a psicanalista.

Indico-lhes que meu envolvimento com a psicanálise de orientação lacaniana data de 1986, e, mesmo tendo frequentado anteriormente duas outras escolas, foi somente a partir de minha entrada na Escola de Psicanálise dos Fóruns do Campo Lacaniano (EPFCL), inicialmente como membro de formações clínicas, depois como membro de fórum, ocupando funções distintas em diferentes momentos, é que a pergunta sobre a formação se impôs. A partir daí, tornar-me membro de Escola foi consequência. Todavia, não posso deixar de lembrar que há um antecedente lógico a meu engajamento. Esse antecedente chama-se uma psicanálise. Cito Lacan, na "Nota anexa ao Ato de fundação":

Porque a Escola, seja qual for o momento em que o sujeito entre em análise, tem que pesar esse fato na balança com a responsabilidade, da qual não pode declinar, de suas consequências. É constante que a psicanálise tenha efeitos sobre toda e qualquer prática do sujeito que nela se engaja. Quando esta prática provém, por pouco que seja, de efeitos psicanalíticos, ele se descobre a gerá-los no lugar em que se espera que os reconheça. (Lacan, 1971/2003d, p. 241)

Mas, antes, voltemos a Freud, para extrair ao menos três lições: primeiro, que a formação do psicanalista implica um nítido embargo à sua pessoa; segundo, 
que esse embargo depende estritamente de que o praticante submeta-se a uma psicanálise; e, terceiro, que dessa formação depende a possibilidade de êxito de sua operação. Curiosamente, de um lado, nos textos de 1912 que versam sobre a técnica, encontramos severas restrições a que o psicanalista opere com sua pessoa, e, de outro, em 1926, a constatação de que o aluno a quem ministramos instrução teórica só adquire convicção da psicanálise se sua pessoa for afetada por aquilo que Freud (1926/1987b, p. 226) chamou em nota de rodapé de uma análise didática. Deixemos registradas tais indicações, pois trago a pergunta se não poderíamos aí localizar um primeiro paradoxo do desejo na formação do psicanalista, ou, até mesmo para sermos mais rigorosos, poderíamos modificar o título e falar dos paradoxos do desejo do psicanalista. No dicionário etimológico, encontramos para paradoxo: do latim para, que podemos traduzir por "contrário", "ir de encontro" + doxum, "opinião" = paradoxum. Paradoxum, então, significaria um conceito contrário à opinião comum. Assim, é um paradoxo que o analista não opere com sua pessoa, todavia ele a empresta, suportando os fenômenos singulares da transferência. Mais ainda: essa pessoa, que deve ficar fora do jogo, deve ser afetada no fim de uma análise, de tal modo que o saldo dessa operação poderia ser chamado de desejo do psicanalista. Estranho desejo que vai contra. Contra a pessoa, mas a favor do desejo...

Conjugaremos, então, o desejo do psicanalista com o ato analítico, na medida em que esse ato implica uma operação de transformação, uma espécie de mutação no ser.

Falemos primeiro sobre os embargos infligidos à pessoa do analista. Encontramos inúmeras indicações em "Recomendações aos médicos que exercem a psicanálise" (1912/1987a). Nesse trabalho, Freud coloca o analista na berlinda, como Lacan bem observou em “A direção do tratamento e os princípios do seu poder” (1958/1998). Vejamos. O analista paga com sua pessoa, "na medida em que, haja o que houver, ele a empresta aos fenômenos singulares que a análise descobriu na transferência" e "paga com o que há de essencial em seu juízo mais íntimo, para intervir numa ação que vai ao cerne do seu ser: seria ele o único a ficar fora do jogo?” (Lacan, 1958/1998, p. 593). Voltemos às Recomendações para extrair daí os trechos nos quais Freud propõe claramente o que estou chamando de embargo à pessoa do analista:

a) $\mathrm{O}$ analista equivoca-se no processo de recordação daquilo que o paciente fala apenas quando se acha perturbado por alguma consideração pessoal, isto é, quando se caiu seriamente abaixo do padrão de um analista.

b) Os casos mais bem-sucedidos são aqueles em que se avança sem qualquer intuito em vista, em que se permite ser tomado de surpresa, sem pressuposições. Portanto, o interesse científico do psicanalista a respeito do caso é visto com reservas por Freud. 
c) Freud propõe uma "frieza emocional" por parte do psicanalista. Para o médico, diz ele, é a proteção desejável para sua própria vida emocional e, para o paciente, o maior auxílio que podemos hoje dar.

d) O médico deve voltar seu próprio inconsciente, como um órgão receptor, na direção do inconsciente transmissor do paciente. Mas, para estar em posição de utilizar seu inconsciente desse modo, como instrumento da análise, deve ele preencher determinada condição psicológica em alto grau. Não basta que o médico seja uma pessoa aproximadamente normal para dar conta da tarefa. Ele deve ter passado por uma purificação psicanalítica, ficando ciente dos complexos que poderiam interferir na apreensão daquilo que o paciente lhe diz, pois todo recalque nele não solucionado constitui um "ponto cego" em sua percepção analítica.

e) Freud condena a técnica da reciprocidade afetiva. Adverte que os jovens analistas tendem a colocar sua própria individualidade no debate com o paciente, como se, dando-lhe informações íntimas de sua vida, pudesse capacitá-lo melhor, colocando-se em pé de igualdade com ele. Mas a experiência não fala em favor de uma técnica afetiva desse tipo. Essa técnica implica um afastamento dos princípios psicanalíticos e beira o tratamento por sugestão.

f) O médico deve ser opaco a seus pacientes e, como um espelho, não lhes mostrar nada, exceto o que lhe é mostrado.

g) O médico deve controlar-se e guiar-se pelas capacidades do paciente, em vez de por seus próprios desejos. A ambição educativa é de tão pouca utilidade quanto a ambição terapêutica.

Nesse texto de 1926, Freud refere-se aos três institutos de formação psicanalítica existentes na ocasião, em Berlim, Viena e Londres, onde os candidatos eram submetidos à análise, recebiam instrução teórica, desfrutavam da supervisão de analistas mais experimentados e faziam suas primeiras incursões com casos mais brandos. Ainda assim eram principiantes. O que ainda necessitavam deveria ser adquirido pela prática e pela troca de ideias nas sociedades psicanalíticas, nas quais jovens e velhos se encontrariam. Portanto, estaria, a partir de então, estruturado o famoso tripé freudiano da formação: análise, supervisão e estudo dos textos (Freud, 1926/1987b, pp. 258-259). O que podemos incluir no tripé de Freud é a novidade trazida por Lacan em 1964, quando funda sua Escola, a Escola Francesa de Psicanálise, após seu ensino ser proscrito pela Sociedade Psicanalítica de Paris, cuja aspiração era ser aceita pela Associação Psicanalítica Internacional (IPA, na sigla em inglês para International Psychoanalytical Association). Assim, poderíamos reescrever, atualizando a questão: o analista depende de sua análise para estar à altura de sua tarefa, mas ainda não é o bastante. Se a análise pessoal é da ordem da necessidade orquestrada por um querer, pode-se ainda desejar uma Escola, 
uma "Escola como experiência inaugural", na qual Lacan deixará a cargo de cada um "descobrir suas promessas e seus obstáculos" (Lacan, 1971/2003d, p. 242).

No "Ato de fundação", Lacan define que "um psicanalista é didata por ter feito uma ou mais psicanálises que se tenham revelado didáticas" (Lacan, 1971/2003d, p. 239). Trata-se de uma habilitação de fato, e não de direito. Rompe, assim, com os parâmetros da IPA, pois nesse tipo de sociedade o acesso ao título de didata dependia não do consentimento dos pares, mas do pertencimento à "lista". O título de didata vinha como uma consagração. Mas não se sabia exatamente como isso acontecia: era o que ficava na sombra. A fundação de sua Escola constituiu uma forma de tratamento aos problemas relativos à formação e à qualificação do psicanalista, pois que no coração de sua Escola colocou o passe e a garantia. Então, na Escola fundada por Lacan:

- A "lista” de didatas fica abolida, e o analisante é livre para escolher seu analista.

- O psicanalista só se autoriza por si mesmo, mas deve dar suas provas perante alguns outros.

- Espera-se que os dispositivos inventados por Lacan estejam à altura de fazer essa verificação ou recolher essas provas, distinguir suas marcas. Ainda que não se possa dizer o que é o psicanalista, senão um psicanalista, outro psicanalista e ainda outro psicanalista. Um de cada vez, assim como se contam as mulheres.

- Por fim, para remediar o mal-estar, na Escola os psicanalistas abrigam-se para fazer um conjunto que, no entanto, não fecha nunca. Só há o que Lacan (1976/2003f, p. 569) chamou de "esparsos disparatados".

Retomemos o "Ato de fundação" e sua nota anexa, pois, desde que fiz a primeira leitura desse texto, uma frase insiste em ressoar. Ao falar da análise didática, Lacan diz:

O único princípio certeiro a formular, ainda mais por ter sido desconhecido, é que a psicanálise constitui-se como didática pelo querer do sujeito, e que ele deve ser advertido de que a análise contestará esse querer, na medida mesma da aproximação do desejo que ele encerra. (Lacan, 1971/2003d, p. 240)

Trago a hipótese de que, nessa formulação, podemos localizar um segundo paradoxo do desejo na formação do psicanalista. Vamos desdobrar a questão:

1) Aqueles que empreendem uma psicanálise didática o fazem por sua iniciativa e escolha (seu querer), diz Lacan.

2) No entanto, o sujeito deve ser advertido de que a análise contestará esse querer, na medida da aproximação do desejo que ele encerra. 
Qual é o desejo que esse querer encerra? Não seria justamente a emergência do desejo do psicanalista que contestaria esse querer?

Na "Proposição de 9 de outubro de 1967 sobre o psicanalista da Escola”, podemos vislumbrar algumas indicações para prosseguir. Lacan (1967b/2003b, p. 257) dirá que "o término de uma psicanálise superfluamente chamada de didática é, com efeito, a passagem do psicanalisante a psicanalista".

No fim dessa operação, temos o término da relação transferencial:

(...) havendo-se resolvido o desejo que sustentara em sua operação o psicanalisante, ele não tem mais vontade, no fim, de levantar a sua opção, isto é, o resto que, como determinante de sua divisão, o faz decair de sua fantasia e o destitui como sujeito. (Lacan, 1967b/2003b, p. 257)

A isso Lacan chamou destituição subjetiva: "Se a destituição subjetiva está já gravada no bilhete de ingresso", pergunta Lacan, "não será isto a provocar o horror, a indignação, o pânico ou até o atentado, ou, pelo menos, dar um pretexto para a objeção de princípio?” (Lacan, 1967b/2003b, p. 257).

Todavia, ele continua, "falar da destituição subjetiva jamais deterá o inocente, que não tem outra lei senão seu desejo" (Lacan, 1967b/2003b, p. 258).

Assim, do lado do analisante, temos a destituição subjetiva e, do lado do analista, um golpe em seu ser.

Lacan introduz algo novo: a função do desejo, em contraposição à norma, à burocracia, aos jogos políticos e à enfatuação, e mesmo ao que se chamaria desejo de ser psicanalista. O desejo do psicanalista, portanto, deve ser diferenciado do desejo de ser psicanalista. A demanda de ser psicanalista é demanda de formação e está do lado da demanda neurótica: é demanda de amor, de ser reconhecido, enfim, de se profissionalizar, e não desemboca necessariamente no desejo do psicanalista. O desejo do psicanalista, portanto, não é o destino natural de uma análise, ponto a que todo analisante chegaria naturalmente, como quando se cumpre um programa, senão que esse desejo só pode ser concebido como consequência do ato analítico, e é certo que ele não se coloca para todos os que se submetem a uma psicanálise.

O desejo do psicanalista é o que não estava no programa. Essa travessia implica um salto e sobrevém de a-salto, colhe o psicanalisante.

Lacan nos diz que esse desejo, advindo no final de uma análise, como todo desejo, não é articulável, pois não se pode analisá-lo, não se pode subjetivá-lo, não se pode interpretá-lo. É um ato de decisão. Se esse desejo é solidário do ato, depois disso nada será como antes. A imagem que Lacan nos oferece dessa passagem no seminário do ato analítico (1967a, inédito) é a de César atravessando 
o Rubicão. Não se pode voltar atrás. César avança sobre uma terra que não era a sua, tomando posse, autorizando-se. Uma decisão que modifica, faz tremer os alicerces. Assim, diremos que essa passagem de psicanalisante a psicanalista é um salto, e o passe é o procedimento inventado por Lacan para que se diga como se deu esse salto. Como diria Adélia Prado, escritora mineira, é como pegar um peixe vivo com a mão: puro susto e terror (Prado, 1976/2008). Lacan não utiliza o mesmo termo que minha conterrânea. Certamente, haveria sutilezas semânticas que nos impediriam de homogeneizar os termos horror e terror. Mas a imagem do susto, da surpresa ou do inédito serve-nos bem aqui. Lacan fala do horror para se referir a esse momento muito particular que marca o início do fim de uma psicanálise. Passado o horror correlativo ao ato, ainda é preciso que se fale disso, que se transmita como se pôde chegar a esse ponto, como se operou esse salto, no fim das contas: "explorar este salto é o que chamei de passe" (Lacan, 1967a, p. 258, inédito). Mas, por qual razão Lacan fala de horror? Qual a relação entre o horror do ato e o desejo do psicanalista? É porque nessa "passagem de psicanalisante a psicanalista tem uma porta cuja dobradiça é o resto que constitui a divisão entre eles, porque essa divisão não é outra senão a do sujeito, da qual esse resto é a causa” (Lacan, 1967a, p. 259, inédito).

Nessa reviravolta — passagem de psicanalisante a psicanalista —, o analisante vê soçobrar a segurança que extraía de sua fantasia, que era sua janela para o real: "o que se percebe é que a apreensão do desejo não é outra coisa senão a de um des-ser" (Lacan, 1967a, p. 259, inédito).

Voltemos, então, ao início, quando Lacan perguntava se essa destituição subjetiva que já estava gravada no bilhete de entrada, e que poderia provocar o pânico, a indignação e o horror, não toma agora seu acento. Consentiria o analisante nessa nova condição? Consentiria ele em pegar o bastão? Pois, tendo aberto mão de sua pessoa, tendo sido desferido um golpe em seu ser, só lhe resta operar do lugar da causa de sua própria divisão.

Então, se adveio para alguém, no percurso de uma análise, o desejo inédito de se colocar para alguns outros como suportando o lugar da causa, e sendo essa operação consentida, posto que implica uma queda do sujeito suposto saber e sua redução ao advento do objeto $a$, essa operação deve deixar uma marca. Marca que fica cravada do lado do desejo e que consiste em ocupar daí em diante, para alguém, o lugar de suposto saber "sem perceber", diz Lacan, na lição de 10 de janeiro de 1967:

Aquele que, no fim de uma análise didática, aceita se posso dizer, o desafio desse ato, não podemos omitir que é sabendo o que seu analista se tornou na efetuação desse ato, a saber, esse resíduo, esse dejeto, essa coisa rejeita- 
da. Ao restaurar o sujeito suposto saber, ao retomar ele próprio a tocha do analista, é impossível que ele não se instale, ainda que sem perceber, que ele não instale o " $a$ ", no nível do sujeito suposto saber. Esse sujeito suposto saber, que ele tem que retomar como condição do ato analítico, ele sabe, nesse momento que chamei de passe, ele sabe que lá está o des-ser, que por ele, o psicanalisando, feriu o ser do analista. Digo "sem perceber", pois é assim que ele se engaja. Pois, desse saber, ele, o sujeito no passe, nada sabe a seu respeito. Isso, justamente, porque ele se tornou a verdade desse saber e, se posso dizer assim, uma verdade é atingida "não sem o saber (pas sans le savoir), como dizia há pouco... bem, é incurável: somos essa verdade. (Lacan, 1967a, p. 90, inédito)

No fim de uma análise, o analista é rejeitado, como estrume. O saber que era suposto ao psicanalista, o analisante passa a sê-lo, encarná-lo. Mas a paz não vem selar essa metamorfose em que o parceiro se desvanece. Se "é impossível falar disso sozinho" (Lacan, 1967a, inédito), pode-se desejar entrar no dispositivo do passe para aferir essa viragem de psicanalisante a psicanalista. Ainda que o dispositivo tenha furos, em uma Escola não podemos abrir mão dele. É no dispositivo que se torna possível reconhecer essa marca, esse label, pois "ele tem esse 'label', ou então ele não é”, diz Lacan, na mesma lição.

Finalizando, digo que nessa passagem ninguém sai ileso. O psicanalista vira estrume pelo golpe desferido em seu ser, e o psicanalisante consente em ocupar a função de objeto agalmático para alguns outros, na condição de que lhe tenha ocorrido uma destituição subjetiva. Contrariamente à opinião comum, entre mortos e feridos, ninguém se salva. Surge um novo desejo. O desejo do psicanalista. O trabalho árduo que fica para a Escola é saber recolher suas marcas. Sempre singulares.

Encerro com Restos, de Carlos Drummond de Andrade:

O amor, o pobre amor estava putrefato.

Bateu, bateu à velha porta, inutilmente.

Não pude agasalhá-lo: ofendia-me o olfato.

Muito embora o escutasse, eu de mim era ausente.

(Andrade, 1996) 


\section{Referências bibliográficas}

Andrade, C. D. (1996). Restos. In C. D. Andrade. Farewell. Rio de Janeiro: Record. Fingermann, D. (2016). A (de)formação do psicanalista: as condições do ato analítico. São Paulo: Escuta.

Freud, S. (1987a). Recomendações aos médicos que exercem a psicanálise. In S. Freud. Artigos sobre técnica: edição standard brasileira das obras completas de Sigmund Freud (Vol. 12). Rio de Janeiro: Imago. (Trabalho original publicado em 1912)

Freud, S. (1987b). A questão da análise leiga. In. S. Freud. Edição standard brasileira das obras completas de Sigmund Freud (Vol. 20). Rio de Janeiro, Imago. (Trabalho original publicado em 1926)

Lacan, J. (1967a). O seminário, livro XV: o ato psicanalítico. Inédito.

Lacan, J. (1998). A direção do tratamento e os princípios do seu poder. In J. Lacan. Escritos. Rio de Janeiro: Jorge Zahar. (Trabalho original publicado em 1958)

Lacan, J. (2003a). Ato de fundação. In J. Lacan. Outros escritos. Rio de Janeiro: Jorge Zahar. (Trabalho original publicado em 1964)

Lacan, J. (2003b). Proposição de 9 de outubro de 1967 sobre o psicanalista da escola. In J. Lacan. Outros escritos. Rio de Janeiro: Jorge Zahar. (Trabalho original publicado em 1967b)

Lacan, J. (2003c). Discurso na Escola Freudiana de Paris. In J. Lacan. Outros escritos. Rio de Janeiro: Jorge Zahar. (Trabalho original publicado em 1970)

Lacan, J. (2003d). Nota anexa ao Ato de fundação. In J. Lacan. Outros escritos. Rio de Janeiro: Jorge Zahar. (Trabalho original publicado em 1971)

Lacan, J. (2003e). Nota italiana. In J. Lacan. Outros escritos. Rio de Janeiro: Jorge Zahar. (Trabalho original publicado em 1973)

Lacan, J. (2003f). Prefácio à edição inglesa do Seminário 11. In J. Lacan. Outros escritos. Rio de Janeiro: Jorge Zahar. (Trabalho original publicado em 1976)

Prado, A. (2008). Antes do nome. In A. Prado. Bagagem. Rio de Janeiro: Record. (Trabalho original publicado em 1976)

Quinet, A. (2000). As 4+1 condições da análise (9a ed.). Rio de Janeiro: Jorge Zahar. Quinet, A. (2003). A descoberta do inconsciente: do desejo ao sintoma (2a ed.). Rio de Janeiro: Jorge Zahar.

Quinet, A. (2009). A estranheza da psicanálise: a escola de Lacan e seus analistas. Rio de Janeiro: Jorge Zahar.

Recebido: 29/06/2019

Aprovado: 29/06/2019 